\title{
To Ascertain the True or Faking and Ingredients of Silver-Coins by Using Specific Weight
}

\author{
Kuo Ming Huang ( $\nabla$ kmhuang@mail.ntou.edu.tw ) \\ National Taiwan Ocean University \\ Ming-Hung Hsu \\ National Taiwan Ocean University \\ Jang-Ping Wang \\ National Taiwan Ocean University
}

\section{Research article}

Keywords: Silver-coins, Specific weight, Nonlinear constrain method, Archimedes' Principle, Identification of coins

Posted Date: August 18th, 2020

DOl: https://doi.org/10.21203/rs.3.rs-59702/v1

License: @ (i) This work is licensed under a Creative Commons Attribution 4.0 International License. Read Full License 


\title{
To ascertain the true or faking and ingredients of silver-coins by using specific weight
}

\author{
Kuo-Ming Huang ${ }^{1 *}$, Ming-Hung Hsu ${ }^{1}$, Jang-Ping Wang ${ }^{1}$ \\ ${ }^{1}$ Dept. of Marine Engineering, National Taiwan Ocean University, 2 Pei-Ning Road, Keelung, Taiwan \\ 202-24, R.O.C.
}

\begin{abstract}
The early twenty-first century has witnessed forgeries of antique silver coins (including Japanese coins, Qing Dynasty coins, Yuan-Shikai-era coins, and Republic of China coins). Some forgers wallow in extravagant profits from illegal trading in fake coins with correct weights that combine some silver with cheaper metals. Exceptional forgers can deceive coin collectors by delivering mostly silver pieces of the same weights and sizes as genuine silver coins. Specific gravity is the ratio of masses for equal volumes of different substances; even though numerous forgers understand coin weights and thus deliver fake products with the correct weights, the aforementioned forgery process cannot counterfeit the specific gravity values of silver coins. Hence, the specific gravity values of silver products can be used to distinguish genuine coins from counterfeits. This paper explains a multistep process for distinguishing genuine from counterfeit silver coins. Calculations of specific gravity are combined with a nonlinear constraint method to estimate the ingredients of alleged silver coins. When the ingredients of a coin have been ascertained, whether a coin is genuine or counterfeit can be proven.
\end{abstract}

Keywords: Silver-coins, Specific weight, Nonlinear constrain method, Archimedes' Principle, Identification of Coins

*Corresponding author: Tel: +886-2-24622192 ext. 7102; E-mail address: kmhuang@mail.ntou.edu.tw 


\section{Introduction}

Anyone who buys antique silver coins must avoid buying counterfeits. The first test of genuineness is the weight of the alleged silver coin. Unfortunately, a counterfeiter can easily fabricate a partly silver product that has the same weight as a genuine silver coin [1]. For example, the silver coin weight of Japan dragon is $26.96 \mathrm{~g}$ [2-3]. A counterfeiter can use cheaper metals, such as lead, copper, and iron, to make a product that appears to be a silver coin of the correct weight. This paper proposes a method called specific gravity technology to inspect the metal composition of an alleged silver coin. The specific gravity can be measured regardless of the size and weight of the alleged silver piece [4].

Archimedes' Principle, which pertains to a body that is completely or partially submerged in a water at rest, states that the magnitude of the upward, or buoyant, force acting on the body is equal to the weight of the fluid displaced by the body [5-6]; this displaced water can be used to measure the specific gravity. The volume of displaced fluid is equivalent to the volume of an object fully immersed in water or to that fraction of the volume below the surface for an object partially submerged in a liquid. Such as $5-\mathrm{kg}$ object immersed in water is acted upon by a buoyant (upward) force of $19.613 \mathrm{~N}$, which is equal to the force of the weight of the $2 \mathrm{~L}$ of water displaced by the immersed object. The buoyant force reduces the object's apparent weight by $2 \mathrm{~kg}$ - that is, from $5 \mathrm{~kg}$ to $3 \mathrm{~kg}$. Hence, the specific gravity of this subject is its density divided by water density, which is equal to 2.5 .

A method of nonlinear constraints [7-11] can be used to determine the ingredients of silver coins. Forgers construct counterfeit products from combinations of different metals (Table 1) — such as pure silver, pure copper, pure iron, stainless, pure lead and nickel (which have different specific gravity values). A counterfeit coin's weight, size, and surface image may be almost exactly the same as those of a corresponding genuine coin. However, numerous counterfeit coins have blatantly wrong specific gravity values. A counterfeit that does not perfectly match the metal composition of the corresponding genuine coin can be detected through its specific gravity value.

\section{Technology design and experimental tests}

A self-made device for measuring specific gravity method is depicted in Fig. 1. Fig. 2 shows two Japanese dragon silver coins of approximately equal weight (left: $26.9065 \mathrm{~g}$; right: $24.2999 \mathrm{~g}$ ) were placed in the experimental device. Here the left-hand-side object weighed $26.9065 \mathrm{~g}$; when it was immersed in water, it was acted upon by a buoyant (upward) force equivalent to the force from $(26.9065-24.2999 \mathrm{~g})$ $2.6066 \mathrm{~g}$ of water, which is the weight of the $2.6066 \mathrm{~L}$ of water displaced by the immersed object. Hence, the specific gravity of this object was $10.3224\left(\mathrm{~g} / \mathrm{cm}^{3}\right)$. For 
the right-hand-side coin, the steps were repeated again and the specific gravity obtained was $8.9001(\mathrm{~g} / \mathrm{L})$. It was found that the left coin is genuine because its density is $10.3224\left(\mathrm{~g} / \mathrm{cm}^{3}\right)$ and the right is counterfeit because its density is 8.9001 $\left(\mathrm{g} / \mathrm{cm}^{3}\right)$. Thus, the measurements revealed one silver coin to be genuine and the other to be counterfeit. The measurement is accurate to three decimal places of a gram.

Table 2 lists experimental results for six specimens in terms of weight $(\mathrm{g})$, diameter $(\mathrm{mm})$, volume $\left(\mathrm{cm}^{3}\right)$, and density $\left(\mathrm{g} / \mathrm{cm}^{3}\right)$. In this table, $\pm 2 \%$ error range was considered acceptable for the tests.

Specimens 3 and 8 have specific gravity values less than $10.3224\left(\mathrm{~g} / \mathrm{cm}^{3}\right)$ and can be judged as counterfeit silver coins. Note that specimen 3 weighs $26.6 \mathrm{~g}$, which is close to the weight of a genuine silver coin.

The quantities of six component metals can be calculated through discrete-mathematical methods.

\section{Approach of nonlinear constrain method}

Six relevant components (pure silver, pure copper, pure iron, pure lead, pure zinc, and pure nickel) have different specific gravity and density values. From experimental data, we can obtain the volume and its specific gravity, and the density values of silver coins can be calculated as:

$$
\mathrm{W}_{\text {silver-coin }} / \mathrm{V}_{\text {silver-coin }}=\text { specific weight }
$$

For a genuine silver coin:

$$
\mathrm{W}_{\text {silver-coin }} / \mathrm{V}_{\text {silver-coin }}=10.3224
$$

Each component has its known specific gravity and the calculations assume the weight of each unknown component as $X_{i}$ and each known specific gravity as $\mu_{i}$. The total volume is then necessarily:

$$
\sum_{i=1}^{6} X i / \mu i=\mathrm{V}_{\text {silver-coin }}
$$

with the constraints:

$$
\begin{gathered}
\sum_{i=1}^{6} X i=\mathrm{W}_{\text {silver-coin }} \\
\sum_{i=1}^{6} X i / \mathrm{W}_{\text {silver-coin }}=1
\end{gathered}
$$




$$
0 \leq\left(\mathrm{X}_{\mathrm{i}} / \mathrm{W}_{\text {silver-coin }}\right) \leq 1
$$

The weight of specimen 8 is $22.92 \mathrm{~g}$, whereas the weight of a true silver coin is $26.96 \mathrm{~g}$; the alleged silver coin is counterfeit. The weight of specimen 3 is $26.6 \mathrm{~g}$ and approximately equal to the true value of $26.96 \mathrm{~g}$. However, the density $\left(8.9001 \mathrm{~g} / \mathrm{cm}^{3}\right)$ is not equal to the true density $\left(10.3224 \mathrm{~g} / \mathrm{cm}^{3}\right)$; thus, specimen 3 is counterfeit.

\section{Results and discussion}

To inspect whether the silver coins is counterfeit, the first step is to measure the weight of the silver coins (the true weight is $26.96 \mathrm{~g}$ ). According to this test, specimen 8 (weight $=22.92 \mathrm{~g}$ ) is clearly counterfeit. The second step is to check the specific gravity values. Specimen 3 weighs $26.6 \mathrm{~g}$ (with a $\pm 2 \%$ error range), which is close to its true value. The density of specimen 3 is $8.9 \mathrm{~g} / \mathrm{cm}^{3}$, whereas the density of silver is $10.3224 \mathrm{~g} / \mathrm{cm}^{3}$; thus, specimen 3 is a counterfeit coin.

The third step is to calculate and obtain, from the weight and volume of silver coins, the ingredients of both genuine and counterfeit silver coins. For example, specimen 1 has a weight of $26.90 \mathrm{~g}$, a volume of $2.61 \mathrm{~mL}$, and a density of $10.3 \mathrm{~g} / \mathrm{cm}^{3}$; it is thus certainly a genuine silver coin. As calculated using Eq. 3, we determine that the component weight of pure silver is $24.3080 \mathrm{~g}$ and that of copper is $0.9036 \mathrm{~g}$ (thus specimen 1 is $90.36 \%$ silver and $9.635 \%$ copper by percentage weight). It is therefore a genuine silver coin (within a $\pm 2 \%$ error range).

To calculate the ingredients of specimen 3 , one must recall that the density of pure lead is greater than that of pure silver $\left(10.3224 \mathrm{~g} / \mathrm{cm}^{3}\right)$, where pure lead was selected as the main metals. Other metals (such as pure iron, stainless steel, pure copper, and pure nickel) can be investigated as possible component metals. It was found that (1) pure lead with pure copper, and (2) pure lead with pure nickel both fail to combine with each other (negative answers). Pure lead and pure iron can be combined with each other, but such combinations lead to impractical levels of corrosion. Hence, pure lead and stainless (SUS430-SUS210, specific gravity: 7.7-7.93 $\mathrm{g} / \mathrm{cm}^{3}$ ) samples were used. In this study, the minimum (pure lead: $9.17 \mathrm{~g}$, stainless steel: $17.42 \mathrm{~g}$ ) and maximum (pure lead: $11.05 \mathrm{~g}$, stainless steel: $15.54 \mathrm{~g}$ ) specific gravities of stainless steel were verified to be suitable for the construction of counterfeit coins. Table 3 lists the ingredients of specimens 1 to 8 . From this table, the ingredients of specimens 3 and 8 (counterfeit coins) can be proven counterfeit, and the ingredients of genuine coins can be verified. 


\section{Conclusions}

Three steps are sufficient to detect counterfeit coins. The first is to check the weight of the alleged silver coin. The measured value can be compared with the correct value (26.96 g). Second, if the alleged silver specimen does not have a density of $10.3224 \mathrm{~g} / \mathrm{cm}^{3}$, it is counterfeit silver. Third, one must calculate the ingredients of the coins to prove what is genuine and what is counterfeit. One must solve simultaneous equations with constraints to calculate these ingredients.

From this discussion, the following conclusions are drawn:

(1) Alleged silver coins can be verified through weight inspection.

(2) Density measurements can detect fake coins, such as specimen 8.

(3) The calculation of component metals can reveal that some fake coins with the correct weight do not contain pure silver. For example, specimen 3 seems to have the correct weight, but it is mainly composed of base metals. 


\section{References}

[1] JP Wang, YC Jheng, GM Huang, JH Chien. Artificial neural network approach to authentication of coins by vision-based minimization. Machine Vision and Applications. 2011;22:87-98.

[2] Shi CE. Hsuanhuo Coin Magazine. Taipei: Hsuanhuo press; 2004.

[3] Numista. 1 Yen-Meiji large type. IOP Publishing PhysicsWeb. 2017. https://en.numista.com/catalogue/pieces129442.html. Accessed 16 April 2020.

[4] TK Lu. Research on Western Silver Coins Unearthed in Southern Taiwan. Taiwan Historical Research. 2015; doi:10.6354/THR.

[5] N Biggs. Tomas Harriot on the coinage of England. Archive for History of Exact Sciences. 2019;73:361-383.

[6] F Thompson. Archimedes and the golden crown. Physics education. 2008; doi: 10.1088 / 0031-9120 / 43/4/007.

[7] Himmelblau DM. Applied Nonlinear Programming. University of Michigan: McGraw-Hill; 1972.

[8] HA Hegt, RJ de la Haye, NA Khan. A high performance license plate recognition system. IEEE International Conference on Systems, Man, and Cybernetics. 1998; doi:10.1109/ICSMC.1998.727533.

[9] Reinhold Huber, Herbert Ramoser, Konrad Mayer, Harald Penz Michael Rubik. Classification of coins using an eigenspace approach. Pattern Recognition Letters. 2005;26:61-75.

[10] HG Chiu. The recognition of spurious coin by artificial neural network. National Taiwan Ocean University: Master's thesis; 2006.

[11] M Fukumi, S Omatu, F Takeda, T Kosaka. Rotation-invariant neural pattern recognition system with application to coin recognition. IEEE Transactions on Neural Networks. 1992; doi:10.1109/72.125868. 


\section{Declarations}

\section{Availability of data and materials}

All data generated or analysed during this study are included in this published article.

\section{Competing interests}

The authors declare that they have no competing interests.

\section{Funding}

Not applicable.

\section{Authors' contributions}

KM Huang was a major contributor in writing the manuscript and interpreted the data. $\mathrm{MH}$ Hsu did the experiments for calculating specific weight and also organized experiment results and pictures. JP Wang provided samples for the experiment, reviewed the manuscript and made valuable comments of the experiment results. All authors read and approved the final manuscript.

\section{Acknowledgements}

Not applicable.

\section{Authors' details}

${ }^{1}$ Dept. of Marine Engineering, National Taiwan Ocean University, 2 Pei-Ning Road, Keelung, Taiwan 202-24, R.O.C. 
Figures

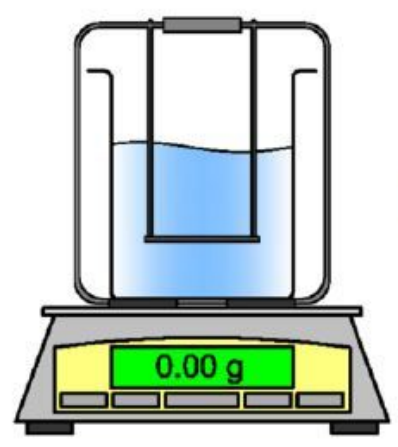

Put beaker on scale and reset

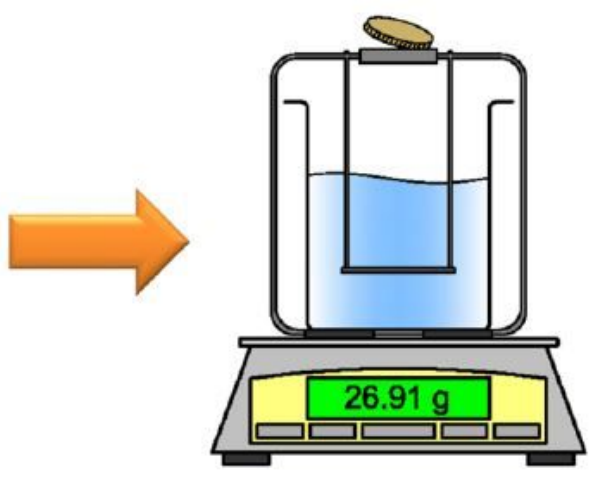

Put coin on the iron stand

(Dry weight)

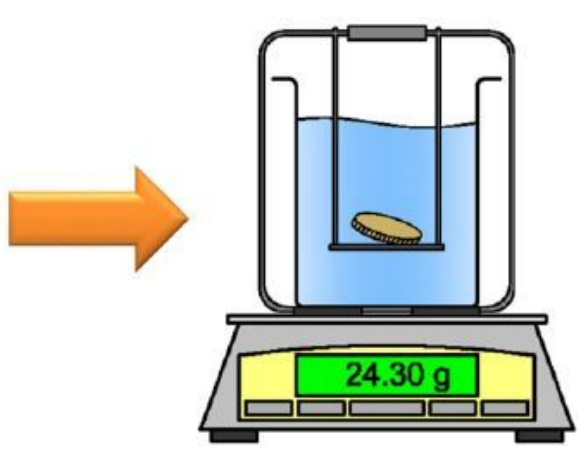

Put coins into water (Wet weight)

Figure 1

Method of measurement coin mass

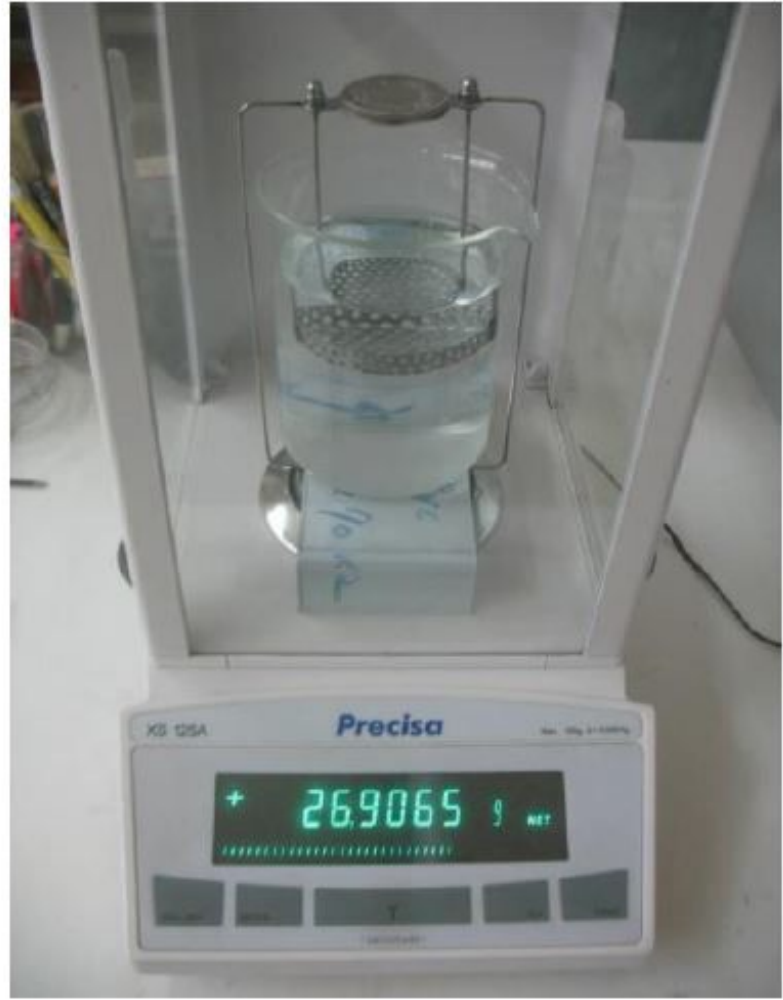

(a) Test samples in the air

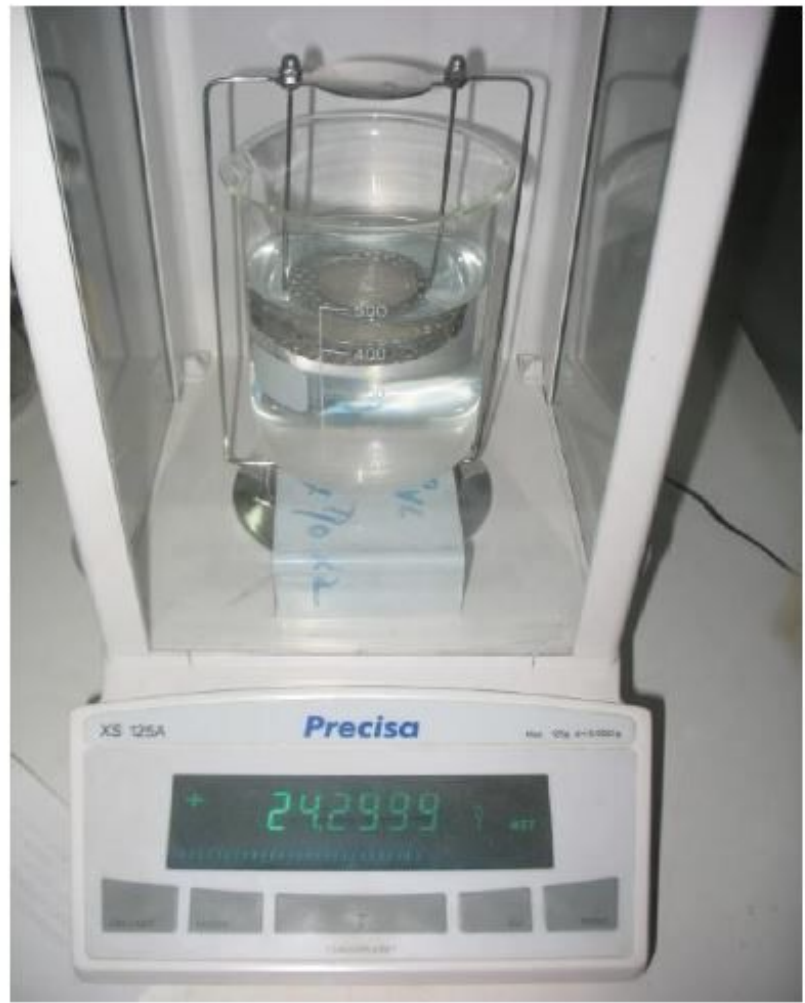

(b) Test samples in the water

Figure 2 
Result of measurement coin mass

\section{Supplementary Files}

This is a list of supplementary files associated with this preprint. Click to download.

- table.pdf

- table.pdf 